\title{
COMUNICAÇÃO
}

\section{AVALIAÇÃO DO ENRAIZAMENTO, DESENVOLVIMENTO DE RAİZES E PARTE AÉREA DE PORTA-ENXERTOS DE VIDEIRA EM CONDIÇÕES DE CAMPO}

\author{
Evaluation of rooting, development of roots and shoot biomass from \\ rootstock of grapevine, in field conditions
}

\author{
Marco Antonio Tecchio', Mara Fernandes Moura', José Luiz Hernandes', \\ Rafael Pio ${ }^{1}$, Patrícia Wyler ${ }^{2}$
}

\begin{abstract}
RESUMO
Objetivou-se neste trabalho avaliar o enraizamento, a brotação e o desenvolvimento de raízes de diferentes porta-enxertos de videira em condições de campo. Estacas lenhosas dos porta-enxertos '420 A', 'Golia', '5C', '8B', 'RR101-14', 'SO4', '99R', 'Kober 5BB', 'IAC 766', 'IAC 572', 'IAC 571-6', 'Ripária do Traviú' e 'Rupestris du Lot' foram colocadas em canteiro de terra, sem tratamento prévio. O delineamento foi em blocos ao acaso, com cinco repetições e vinte estacas por parcela, com as estacas dispostas em espaçamento de $12 \times 5 \mathrm{~cm}$. As estacas foram colocadas para enraizar no início de julho e removidas no final de setembro para as avaliações. A porcentagem de estacas enraizadas variou de 79\% para 'Ripária do Traviú' a 99\% para o 'RR101-14'. Quanto à brotação, o 'Ripária do Traviú' apresentou 47\%, 'IAC 571-6', 'IAC 572', '420 A', 'Rupestris du Lot', 'Kober', 'IAC 766', '8B', '5C', apresentaram de 76 a $89 \%$ e 'Golia', 'SO4', '99R' e 'RR 101-14' mais de 90\%. 'IAC 572' e 'IAC 571-6' apresentaram o menor número de raízes por estaca, no entanto, foram as que apresentaram raízes mais desenvolvidas, seguidas pelo ' $5 \mathrm{C}$ ' $\mathrm{e}$ ' $\mathrm{Rupestris} \mathrm{du}$ Lot'. 'Kober 5BB' e 'Ripária do Traviú' apresentaram as raízes menos desenvolvidas. As demais variedades apresentaram valores intermediários. Concluiu-se que, entre todos os porta-enxertos, o 'Ripária do Traviú' apresentou os menores índices de enraizamento e brotação das estacas, nas condições de campo.
\end{abstract}

Termos para indexação: Vitis spp, propagação e estaquia.

\begin{abstract}
The goals of this investigation was to evaluate the rooting, budding and development of roots from different rootstock of grapevine, in field conditions. Ligneous cutting of rootstock '420 A', 'Golia', '5C', '8B', 'RR101-14', 'SO4', '99R', 'Kober 5BB', 'IAC 766', 'IAC 572', 'IAC 571-6', 'Ripária do Traviú' and 'Rupestris du Lot' were planted in soil, without previous preparation. The experimental design was done in randomized blocks, with five repetitions and twenty cutting per plot, planted at distances of 12 $x 5 \mathrm{~cm}$. The cutting were planted in the beginning of July and removed in the end of September, to be examined. The rooting percentage varied from $79 \%$ of 'Ripária do Traviú' to $99 \%$ of 'RR 101-14'. Due to budding, the 'Ripária do Traviú' showed 47\%; 'IAC 571-6', 'IAC 572', '420A', 'Rupestris du Lot', 'Kober', 'IAC 766', '8B', '5C' showed 76 to 89\% and 'Golia', 'SO4', '99R' and 'RR 10114' showed more than 90\%. 'IAC 572' and 'IAC 571-6' showed the minor root number per cutting, but they showed the most developed roots, followed by ' $5 \mathrm{C}$ ' and 'Rupestris du Lot'. 'Kober 5BB' and 'Ripária do Traviú' showed the least developed roots. The other varieties showed intermediate values. It was conclued that, among all rootstocks, 'Ripária do Traviú' presented the lowest indexes of rooting and budding of cutting under field`s conditions.
\end{abstract}

Index terms: Vitis spp, propagation and cutting.

(Recebido em 27 de setembro de 2006 e aprovado em 23 de fevereiro de 2007)

No Brasil, os vinhedos são formados, em sua maioria, mediante a estaquia lenhosa dos porta-enxertos no final do inverno diretamente no local definitivo ou em recipientes, com posterior plantio em campo (REGINA et al., 1998). A enxertia da cultivar copa nos porta-enxertos enraizados é realizada por garfagem a campo, durante o inverno seguinte (SOUSA, 1996).

Desde meados do século XIX, a enxertia da videira passou a ser uma prática obrigatória, por causa do ataque da filoxera (Daktulosphaira vitifoliae), um pulgão sugador de raízes, que pode causar a morte das videiras da espécie V. vinifera. A partir de então, a utilização de porta-enxertos

\footnotetext{
${ }^{1}$ Pesquisador Científico Centro APTA Frutas, Instituto Agronômico/IAC - Av. Luiz Pereira dos Santos, no 1500, Corrupira - 13214-820 - Jundiaí, SP _ tecchio@iac.sp.gov.br

2Graduanda do curso de Agronomia, Escola Superior de Agricultura "Luiz de Queiroz"/ ESALQ - Universidade de São Paulo/USP - Av. Pádua Dias, 11 13418-900 - Piracicaba, SP.
} 
resistentes ao ataque dessa praga passou a ser a forma de controle mais eficiente (NACHTIGAL, 2001).

A busca de novos porta-enxertos passou então a ser preocupação dos pesquisadores das diversas instituições, principalmente do Instituto Agronômico (IAC) (POMMER, 1993). No entanto, além da resistência à filoxera, um bom porta-enxerto deve possuir adaptação à condições edáficas adversas, facilidade de enraizamento, afinidade com a cultivar copa, bom desempenho vegetativo, grande longevidade e resistência a outras pragas e moléstias (HIDALGO, 1993; SANTOS NETO, 1969). Além de todas essas características, deve-se acrescentar adaptação a solos ácidos, predominantes em São Paulo, influência positiva no desenvolvimento dos cachos, produção e qualidade organoléptica das bagas (SANTOS NETO, 1969).

Considerando-se a área cultivada com videiras no Estado de São Paulo e sua ampla difusão em regiões que apresentam variabilidade de condições de clima e solo, bem como a possível utilização de cultivares que apresentem diferentes níveis de afinidade, é recomendável a utilização de diferentes porta-enxertos que possam atender às finalidades da diversificação (BARROS et al., 1996).

O IAC foi pioneiro no desenvolvimento de diversos porta-enxertos tropicais, entre os quais se destacam o IAC 313 'Tropical', IAC 571-6 'Jundiaí', IAC 572 'Jales' e IAC 766 'Campinas', presentes nas regiões produtoras de uva de mesa, por suas excepcionais qualidades de vigor e adaptabilidade (POMMER, 2001). Além desses porta-enxertos, há um número extenso de porta-enxertos disponíveis aos produtores, como o '420 A', 'Golia', '5C', '8B', 'RR101-14', 'SO4', '99R', 'Kober 5BB', cada um deles apresentando suas vantagens e deficiências. Apenas com a experimentação agrícola podese determinar, com regular precisão, qual o mais adequado para uma determinada cultivar e região (POMMER et al., 1997).

O processo de formação de raízes em estacas de plantas frutíferas é afetado por um grande número de fatores, que podem atuar isoladamente ou em conjunto. Entre os principais fatores destacam-se: a variabilidade genética, a condição fisiológica da planta matriz, a idade da planta, o tipo da estaca, a época do ano, as condições ambientais e o substrato (NACHTIGAL \& PEREIRA, 2000).

Segundo Fachinello et al. (1995), a potencialidade de uma estaca formar raízes é variável com a espécie e também com a cultivar, havendo evidências de que o enraizamento por estacas é controlado geneticamente (HAISSIG, 1982).
Em trabalhos de melhoramento genético de cultivares para porta-enxertos de videira, torna-se fundamental se detectar as reais potencialidades de propagação da cultivar, principalmente no que tange ao enraizamento de suas estacas.

Para avaliar o enraizamento, a brotação e o desenvolvimento da parte aérea e de raízes de diferentes porta-enxertos de videira em condições de campo, realizou-se o presente trabalho.

O trabalho foi realizado no Centro Avançado de Pesquisa Tecnológica dos Agronegócios de Frutas (CAPTA-Frutas), do Instituto Agronômico (IAC).

Os porta-enxertos avaliados foram: ' $420 \mathrm{~A}$ ', 'Golia', '5C', '8B', 'RR101-14', 'SO4', '99R', 'Kober 5BB', 'IAC 766', 'IAC 572', 'IAC 571-6', 'Ripária do Traviú' e 'Rupestris du Lot'. Realizou-se o trabalho com estacas lenhosas das plantas matrizes, apresentando, em média, $6 \mathrm{~mm}$ de diâmetro, 3 a 5 gemas, correspondendo a $30 \mathrm{~cm}$ de comprimento. Foi realizado um corte reto próximo à gema na região basal das estacas e no ápice realizou-se corte em bizel, na porção intermediária do entrenó. Após o preparo das estacas, elas foram colocadas em canteiros de terra, sem tratamento prévio, sendo enterradas a uma profundidade máxima de $2 / 3$ do comprimento. No local da instalação do experimento, o solo é classificado como Cambissolo vermelho distrófico, de acordo com a classificação da Embrapa (1999). Foram realizadas irrigações diárias de modo que o teor de umidade fosse adequado para o enraizamento das mesmas.

O delineamento experimental utilizado foi o de blocos casualizados, com cinco repetições e vinte estacas de cada cultivar por parcela, utilizando-se o espaçamento de 12 x $5 \mathrm{~cm}$. O plantio das estacas foi feito no início de julho 2005 e a retirada no final de setembro (70 dias após o enterrio), avaliando-se as seguintes variáveis: porcentagem de estacas enraizadas com calos e brotadas, massa seca média da raiz e da parte aérea e o número médio de raízes, por estaca.

Com os dados obtidos, realizou-se inicialmente, no programa MINITAB, o teste de normalidade para todas as variáveis avaliadas, com o objetivo de verificar se os dados apresentavam distribuição normal. Posteriormente, os dados foram submetidos à análise de variância e as médias comparadas pelo teste de Tukey utilizando-se o nível de significância de $1 \%$. As análises foram realizadas pelo programa computacional Sistema para Análise de Variância - SISVAR (FERREIRA, 2000). Como os dados não apresentaram distribuição normal, utilizou-se a transformação de dados de porcentagem de estacas 
enraizadas, calejadas e brotadas utilizando-se a fórmula $\operatorname{arcsen} \sqrt{\mathrm{x} / 100}$.

Sendo o experimento realizado em condições de campo, durante a condução realizou-se o levantamento dos dados de temperatura máxima, mínima e média mensal, e precipitação média e acumulada no mês, obtidas na estação meteorológica no Centro de Frutas. As variações ocorridas nesses parâmetros observam-se na Tabela 1.

Para a porcentagem de estacas enraizadas, verificou-se que houve variação de $79 \%$ a $99 \%$ de enraizamento, ou seja, uma amplitude de $20 \%$ entre a cultivar que melhor enraizou, contra o de menor enraizamento. Nesse aspecto, o porta-enxerto 'RR101-14' apresentou o maior valor de enraizamento, estatisticamente superior somente ao 'Riparia de Traviú', 'IAC 571-6' e ao IAC 572 'Jales'. Quanto aos demais porta-enxertos em estudos, pode-se dizer que apresentaram comportamento intermediário (Tabela 2).

Alvarenga \& Fortes (1976) e Biasi et al. (1997) obtiveram enraizamento próximo a $70 \%$ para o porta-enxerto 'Riparia de Traviú' na ausência de AIB, trabalhando com estacas lenhosas e semilenhosas, respectivamente. Já Villa et al. (2003) obtiveram 56,73\% de estacas enraizadas do mesmo porta-enxerto, porém para estacas herbáceas.

A maioria dos porta-enxertos de videira não apresentam grandes dificuldades em enraizar quando propagados por estaquia lenhosa, sendo essa característica herdada de seus progenitores, principalmente das espécies Vitis riparia e Vitis rupestris, que enraizam facilmente (WILLIANS \& ANTCLIFF, 1984). A potencialidade de uma estaca formar raízes é variável com a espécie e também com a cultivar (FACHINELLO et al.,

Tabela 1 - Valores médios de temperatura máxima, mínima e média mensal, em ${ }^{\circ} \mathrm{C}$, e precipitação média e acumulada no mês, em mm, registrados durante a realização do experimento.

\begin{tabular}{cccccc}
\hline & & Temperatura $\left({ }^{\circ} \mathrm{C}\right)$ & \multicolumn{2}{c}{ Precipitação $(\mathrm{mm})$} \\
Mês & Máxima & Mínima & Média & Média & Acumulo total \\
\hline Jul/05 & 23,6 & 10,9 & 17,3 & 1,0 & 31,9 \\
Ago/05 & 27,0 & 12,7 & 19,8 & 0,4 & 12,1 \\
Set/05 & 25,3 & 14,6 & 20,0 & 2,4 & 71,7 \\
\hline
\end{tabular}

Tabela 2 - Resultados médios da porcentagem de estacas enraizadas, calejadas e brotadas, massa seca média das raízes e da parte aérea e número de raízes por estaca, de treze porta-enxertos de videira. IAC, Jundiaí-SP, 2005.

\begin{tabular}{|c|c|c|c|c|c|c|}
\hline \multirow{3}{*}{ Porta-enxerto } & \multicolumn{6}{|c|}{ Variável analisada* } \\
\hline & \multicolumn{3}{|c|}{$\%$ de estacas } & \multicolumn{2}{|c|}{ Massa seca (mg planta $\left.{ }^{-1}\right)$} & \multirow{2}{*}{$\begin{array}{l}\mathrm{N}^{\mathrm{o}} \text { raízes } \\
\text { por estaca }\end{array}$} \\
\hline & Enraizadas & Calejadas & Brotadas & Raiz & Parte Aérea & \\
\hline '420A' & 90 abc & $91 \mathrm{abc}$ & $81 \mathrm{ab}$ & 53,3 bc & $497,8 \quad \mathrm{~b}$ & 6,0 efg \\
\hline 'Golia' & $91 \mathrm{abc}$ & $91 \mathrm{abc}$ & $92 \mathrm{ab}$ & $143,9 \mathrm{a}$ & $152,7 \quad b$ & $11,0 \mathrm{a}$ \\
\hline ‘5C' & $96 \mathrm{ab}$ & $97 \mathrm{ab}$ & $89 \mathrm{ab}$ & $118,7 \mathrm{ab}$ & $402,9 \quad b$ & 9,0 a \\
\hline '8B' & $97 \mathrm{ab}$ & $97 \mathrm{ab}$ & $88 \mathrm{ab}$ & $108,7 \mathrm{abc}$ & 570,6 b & 7,4 bcdef \\
\hline 'RR101-14' & $99 \mathrm{a}$ & 99 a & $97 \mathrm{a}$ & 84,4 abc & $513,1 \quad b$ & 8,5 bcd \\
\hline 'SO4' & $93 \mathrm{abc}$ & $93 \mathrm{abc}$ & $96 \mathrm{ab}$ & 90,7 abc & 394,4 b & 6,9 cdef \\
\hline '99R' & $97 \mathrm{ab}$ & $97 \mathrm{ab}$ & $96 a b$ & 65,7 bc & $430,8 \quad b$ & 8,7 bcd \\
\hline 'Kober 5BB' & $93 \mathrm{abc}$ & $93 \mathrm{abc}$ & $85 \mathrm{ab}$ & $35,8 \mathrm{c}$ & $237,6 \quad b$ & 7,4 bcdef \\
\hline 'IAC 766' & $97 \mathrm{ab}$ & $97 \mathrm{ab}$ & $87 \mathrm{ab}$ & 80,4 abc & $664,8 \quad b$ & 9,2 a \\
\hline 'Riparia de Traviú' & $79 \mathrm{c}$ & $79 \mathrm{c}$ & $47 \mathrm{c}$ & $37,7 \mathrm{c}$ & $304,8 \quad b$ & 7,8 bcde \\
\hline 'IAC 572' & $88 \mathrm{bc}$ & $92 \mathrm{abc}$ & $79 \mathrm{bc}$ & $119,0 \mathrm{ab}$ & $1540,6 \mathrm{a}$ & $4,8 \mathrm{~g}$ \\
\hline 'IAC 571-6' & $82 \mathrm{c}$ & 89 bc & $76 \mathrm{bc}$ & $121,0 \mathrm{ab}$ & $1692,1 \mathrm{a}$ & $5,4 \mathrm{fg}$ \\
\hline 'Rupestris du Lot' & $87 \mathrm{bc}$ & $89 \mathrm{bc}$ & $82 \mathrm{ab}$ & $114,5 \mathrm{ab}$ & 369,0 b & 6,7 defg \\
\hline $\mathrm{CV}(\%)$ & 12,15 & 12,60 & 13,61 & 37,20 & 40,30 & 12,60 \\
\hline
\end{tabular}

*Médias seguidas da mesma letra na coluna não diferem significativamente entre si, pelo teste de Tukey, a $1 \%$ de probabilidade. 
1995). Há evidências de que o enraizamento por estacas é controlado geneticamente (HAISSIG, 1982). De acordo com Wang \& Andersen (1989), as diferenças quanto ao porcentual de enraizamento entre espécies e/ou cultivares podem ser motivadas po um baixo nível de auxinas ou pela falta de cofatores de enraizamento.

Quanto à porcentagem de estacas calejadas e brotadas, pode-se dizer que houve comportamento das cultivares idêntico à porcentagem de enraizamento, sendo que cultivares que apresentaram maior enraizamento de suas estacas, também apresentaram elevada porcentagem de estacas calejadas e brotadas. Ainda que sejam fenômenos independentes, a formação do calo e o aparecimento de raízes adventícias são influenciados, na maioria dos casos, pelos mesmos fatores e podem ocorrer simultaneamente. Não há uma relação direta entre a formação de calos e o enraizamento (FACHINELLO et al., 1995).

Os porta-enxertos '5C', 'IAC 766' e 'Golia' apresentaram maior número de raízes por estaca (acima de nove), sendo que o último foi o que apresentou a maior massa seca média das raízes $(143,9 \mathrm{mg})$; outros porta-enxertos que apresentaram elevada massa seca média das raízes foram: 'IAC 571-6', 'IAC 572', '5C', 'Rupestris du Lot' e '8B'. Os porta-enxertos 'Kober 5BB' e 'Ripária de Traviú' apresentaram raízes menos desenvolvidas (Tabela 2).

Pereira et al. (1976) verificaram que o porta-enxerto 'IAC 766' apresentou maior massa seca de raízes do que o porta-enxerto 'Kober 5BB'.

Quanto à massa seca média da parte aérea, houve destaque apenas para 'IAC 572' e 'IAC 571-6'. Alvarenga \& Fortes (1976), estudando o desenvolvimento de alguns porta-enxertos para videira, destacaram o 'IAC 572' por apresentar maior massa seca das hastes.

Entre os porta-enxertos avaliados, o 'Ripária do Traviú' apresentou os menores índices para o estabelecimento em condições de campo.

\section{REFERÊNCIAS BIBLIOGRÁFICAS}

ALVARENGA, L. R.; FORTES, J. M. Enraizamento e desenvolvimento áereo de alguns porta-enxertos de videira no município de Viçosa. In: CONGRESSO BRASILEIRO DE FRUTICULTURA, 3., 1976, Rio de Janeiro. Anais... Rio de Janeiro: SBF, 1976. v. 2, p. 591-595.

BARROS, J. C. S. M.; POMMER, C. V.; PASSOS, L. R. S.; TERRA, M. M.; SABINO, J. C.; RIBEIRO, I. J. A.; PIRES, E. J. P. Avaliação da capacidade de enraizamento e desenvolvimento vegetativo de genótipos de videira para porta-enxerto. Scientia Agrícola, Piracicaba, v. 53, n. 2/3, p. 285-292, 1996.

BIASI, L. A.; POMMER, C. V.; PINO, P. A. G. S. Propagação de porta-enxertos de videira mediante estaquia semilenhosa. Bragantia, Campinas, v. 56, n. 2, p. 367-376, 1997.

EMPRESA BRASILEIRA DE PESQUISA AGROPECUÁRIA. Sistema brasileiro de classificação do solo. Brasília; Rio de Janeiro, 1999. 42 p.

FACHINELLO, J. C.; HOFFMANN, A.; NACHTIGAL, J. C.; KERSTEN, E.; FORTES, G. R. de L. Propagação de plantas frutíferas de clima temperado. 2. ed. Pelotas: UFPel, 1995. $179 \mathrm{p}$.

FERREIRA, D. F. Análise estatística por meio do SISVAR (Sistema para Análise de Variância) para Windows versão 4.0. In: REUNIÃO ANUAL DA REGIÃO BRASILEIRA DA SOCIEDADE INTERNACIONAL DE BIOMETRIA, 45., 2000, São Carlos. Anais... São Carlos: UFSCar, 2000. p. 255-258.

HAISSIG, B. E. Carbohydrate and amino acid concentration during adventitious root primordium development in Pinus banksiana Lamb. cutting. Foresty Science, [S.1.], v. 28, p. 813-821, 1982.

HIDALGO, L. Tratado de viticultura general. Madrid: Mundi-Prensa, 1993. 983 p.

NACHTIGAL, J. C. Propagação e Instalação da cultura da videira. In: BOLIANE, A. C.; CORRÊA, L. S. (Eds.). Cultura de uvas de mesa: do plantio à comercialização. Ilha Solteria: [s.n.], 2001. 328 p.

NACHTIGAL, J. C.; PEREIRA, F. M. Propagação do pessegueiro (Prunus persica (L.) Batsch) cultivar Okinawa por meio de estacas herbáceas em câmara de nebulização. Revista Brasileira de Fruticultura, Jaboticabal, v. 22, n. 2, p. 208-212, 2000

PEREIRA, F. M.; HIROCE, R.; IGUE, T.; OLIVEIRA, J. C. Pegamento, desenvolvimento e extração de macronutrientes de cinco diferentes porta-enxertos de videira. Bragantia, Campinas, v. 35, p. 47-54, 1976.

POMMER, C. V. Cultivares de uva produzidos ou introduzidos pelo IAC. In: BOLIANE, A. C.; CORRÊA, L. S. (Eds.). Cultura de uvas de mesa: do plantio à comercialização. Ilha Solteria: [s.n.], 2001. 328 p. 
POMMER, C. V. Uva. In: FURLANI, A. M. C.; VIÉGAS, G. P. (Eds.). O melhoramento de plantas no Instituto Agronômico. Campinas: Instituto Agronômico, 1993. 2 v.

POMMER, C. V.; PASSOS, I. R. S.; TERRA, M. M.; PIRES, E. J. P. Variedades de videira para o Estado de São Paulo. Campinas: Instituto Agronômico, 1997. 59 p. (Boletim técnico, 166).

REGINA, M. de A.; SOUZA, C. R. de; SILVA, T. das G.; PEREIRA, A. F. A propagação da videira. Informe Agropecuário, Belo Horizonte, v. 19, n. 194, p. 20-27, 1998.

SANTOS NETO, J. R. A. A cultura da videira. O Agronômico, Campinas, v. 21, n. 5, p. 67-108, 1969.

SOUSA, J. S. I. Uvas para o Brasil. 2. ed.Piracicaba: FEALQ, 1996. $791 \mathrm{p}$.
VILLA, F.; PIO, R.; CHALFUN, N. N. J.; GONTIJO, T. C. A.; COELhO, J. H. C.; DUtRA, L. F. Enraizamento de estacas herbáceas do porta-enxerto de videira 'Riparia de Traviú' tratadas com auxinas. Ciência e Agrotecnologia, Lavras, v. 27, n. 6, p. 14261431, 2003.

WANG, Q.; ANDERSEN, A. S. Propagation of Hibiscus rosasinensis: relations between stock plant cultivar age, environment and growth regulator treatments. Acta Horticulturae, Wageningen, n. 251, p. 289-309, 1989.

WILLIANS, P. L.; ANTCLIFF, A. J. Successful propagation of Vitis berlandieri and Vitis cinerea from hardwood cuttings. American Journal of Enology and Viticulture, Davis, v. 35, n. 2, p. 75-76, 1984. 